07,13

\title{
Электронно-микроскопические исследования образования структурных дефектов в ZnS при облучении электронами с энергией $400 \mathrm{keV}$
}

\author{
(C) Ю.Ю. Логинов ${ }^{1, \uparrow, ~ А . В . ~ Б р и л ь к о в ~}{ }^{2}$, А.В. Мозжерин ${ }^{2}$ \\ ${ }^{1}$ Сибирский государственный аэрокосмический университет им. акад. М.Ф. Решетнева, \\ Красноярск, Россия \\ ${ }^{2}$ Сибирский фредеральный университет, \\ Красноярск, Россия \\ ฯ E-mail: loginov@sibsau.ru
}

(Поступила в Редакцию 1 марта 2016 г.)

Методом просвечивающей электронной микроскопии исследованы кристаллы $\mathrm{ZnS}$, выращенные из газовой фазы, и эпитаксиальные структуры $\mathrm{ZnS} /(001) \mathrm{GaAs}$, выращенные методом металлоорганической парофазной эпитаксии, после облучения in situ в электронном микроскопе при энергии электронов $400 \mathrm{keV}$ и интенсивности $(1-4) \cdot 10^{19} \mathrm{e} / \mathrm{cm}^{2} \cdot \mathrm{s}$. Показано, что при облучении происходит образование мелких дислокационных петель с размерами $2.5-45 \mathrm{~nm}$ и плотностью $1.4 \cdot 10^{11} \mathrm{~cm}^{-2}$, а также пор и выделений новой фазы с размерами $\leq 10 \mathrm{~nm}$. Выделения могут быть идентифицированы с помощью анализа муарового контраста как $\mathrm{ZnO}$ и $\mathrm{ZnO}_{2}$.

\section{1. Введение}

Изучение образования структурных дефектов и изменения свойств облученных полупроводников представляет интерес как с точки зрения повышения их радиационной стойкости, так и ввиду возможности управления свойствами материалов при облучении [1-5]. Разнообразные структурные дефекты, которые формировались в большом количестве в соединениях $A_{2} B_{6}$ в силу низкой энергии дефекта упаковки этих материалов, являются основной причиной деградации полупроводниковых приборов.

Сульфид цинка, относящийся к группе соединений $A_{2} B_{6}$, используется для регистрации заряженных частиц. Высокая эффективность излучательной рекомбинации электронов и дырок данного материала позволяет использовать его в качестве активного элемента полупроводникового лазера. Эпитаксиальные пленки $\mathrm{ZnS}$ пригодны для изготовления коротковолновых оптоэлектронных приборов, что создает возможность повышения плотности оптической информации [6].

Образование структурных дефектов в полупроводниках при облучении электронами можно наблюдать в просвечивающем электронном микроскопе (ПЭМ) в условиях облучения их электронами с высокой интенсивностью $\sim 10^{17}-10^{19} e / \mathrm{cm}^{2} \cdot \mathrm{s}$, что на несколько порядков выше интенсивностей облучения в обычных промышленных ускорителях $\left(\sim 10^{12}-10^{14} e / \mathrm{cm}^{2} \cdot \mathrm{s}\right)$. Это означает, что на площадь, занимаемую одним атомом, падает $\sim 10^{2}-10^{4}$ электронов в секунду.

Образование структурных дефектов в материалах, облученных in situ в высоковольтном электронном микроскопе $(E \geq 1 \mathrm{MeV})$ электронами с энергией выше пороговой энергии образования радиационных дефектов $E_{T}$, хорошо изучено для $\mathrm{Si}, \mathrm{Ge}[3,7]$ и металлов [8-11]. Образование структурных дефектов в $\mathrm{ZnS}$ при облучении электронами с надпороговыми энергиями $\left(E>E_{T}\right)$ изучено недостаточно.

Целью настоящей работы является исследование влияния электронов с энергией $400 \mathrm{keV}\left(E>E_{T}\right)$ на образование структурных дефектов в $\mathrm{ZnS}$.

\section{2. Эксперимент}

Исследовался $n-\mathrm{ZnS}$, легированный галлием, с удельным сопротивлением $\rho \approx 7 \cdot 10^{3} \Omega \cdot \mathrm{cm}$. Кристаллы $\mathrm{ZnS}$ были выращены при $1500^{\circ} \mathrm{C}$ из газовой фазы с помощью модифицированного метода Пайпера и Полича. Перед исследованиями кристаллы механически и химически полировались. Для химической полировки использовался раствор НРС, состоящий из одной части пересыщенного раствора $\mathrm{CrO}_{3}$ в $\mathrm{H}_{3} \mathrm{PO}_{4}$, нагретой до $60^{\circ} \mathrm{C}$, и двух частей концентрированной кислоты $\mathrm{HCl}$. Утончение образцов для электронно-микроскопических исследований проводилось обычным методом ионного травления ионами $\mathrm{Ar}^{+}$с заключительным травлением ионами $\mathrm{I}^{+}$от 5 до $10 \mathrm{~min}$ при ускоряющем напряжении $3 \mathrm{kV}$ и токе $10 \mu \mathrm{A}$. Для полного устранения поверхностных дефектов, образующихся в результате ионного травления, в необходимых случаях тонкую фольгу подвергали химической полировке в течение $2-3$ s в слабом растворе НPC.

Эпитаксиальные слои ZnS были выращены в Даремском университете (Durham University), Великобритания, методом металлоорганической парофазной эпитаксии (MOVPE) на подложках (001) GaAs при $275^{\circ} \mathrm{C}$ с использованием диметилцинка $\left(\mathrm{CH}_{3}\right)_{2} \mathrm{Zn}, \mathrm{H}_{2} \mathrm{~S}$ и $\mathrm{H}_{2} \mathrm{Se}$. Подложки GaAs полировались до зеркального блес- 


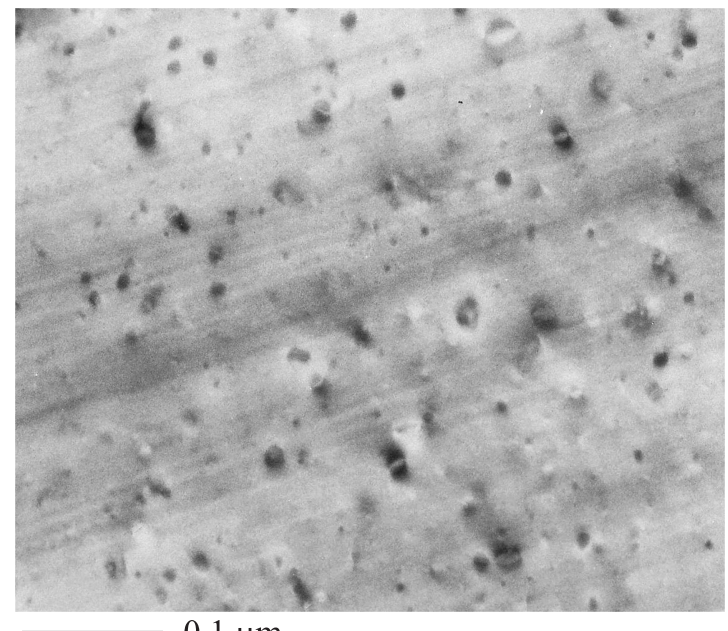

$0.1 \mu \mathrm{m}$

Рис. 1. ПЭМ-изображение структурных дефектов в $\mathrm{ZnS}$, облученном электронами с энергией $400 \mathrm{keV}$ при интенсивности $1 \cdot 10^{19} \mathrm{e} / \mathrm{cm}^{2} \cdot \mathrm{s}$ в течение $5 \mathrm{~min}$.

ка, химически травились в течение $20 \mathrm{~min}$ в растворе $\mathrm{H}_{2} \mathrm{SO}_{4}: \mathrm{H}_{2} \mathrm{O}_{2}: \mathrm{H}_{2} \mathrm{O}=5: 1: 1$, промывались в деионизованной воде и прогревались в потоке водорода в течение 15 min при $500^{\circ} \mathrm{C}$ непосредственно перед выращиванием эпитаксиального слоя.

Облучение тонких фольг $\mathrm{ZnS}$ и $\mathrm{ZnS} / \mathrm{GaAs}$ электронами с энергией $E=400 \mathrm{keV}$, превышающей пороговую энергию образования пар Френкеля, проводилось in situ в электронном микроскопе JEM-4000 EX II при интенсивностях $\sim(1-4) \cdot 10^{19} \mathrm{e} / \mathrm{cm}^{2} \cdot \mathrm{s}$. Электронно-микроскопические исследования проводились на приборах JEM-4000 EX II и JEM-2100.

\section{3. Результаты и обсуждение}

Электронно-микроскопические исследования необлученных кристаллов $\mathrm{ZnS}$ показывают, что в них имеются ростовые дислокации и протяженные дефекты упаковки. Хорошо развитые параллельные полосы (страты), свидетельствующие о политипной модификации $\mathrm{ZnS}$, также наблюдаются во всех случаях. Это особенно сильно проявляется, когда вектор дифракции $\mathbf{g}$ перпендикулярен этим полосам.

Облучение $\mathrm{ZnS}$ электронами с энергией $400 \mathrm{keV}$ in situ в ПЭМ сопровождается формированием мелких дислокационных петель. На рис. 1 показано образование дислокационных петель в $\mathrm{ZnS}$ после облучения электронами в течение $5 \mathrm{~min}$. Размеры дислокационных петель составляют $2.5-45 \mathrm{~nm}$, плотность $1.4 \cdot 10^{11} \mathrm{~cm}^{-2}$. Страты, характерные для политипной модификации кристаллов $\mathrm{ZnS}$, также хорошо видны в виде параллельных линий. Перед электронным облучением приповерхностные слои $\mathrm{ZnS}$ были очищены от дефектов в результате химической полировки в разбавленном растворе НРС.
Дальнейшее облучение электронами $\mathrm{ZnS}$ сопровождается ростом, трансформацией, сокращением и перемещением петель, образованием новых петель, а затем формированием пор. Снимок с высоким разрешением (рис. 2) демонстрирует на атомном уровне образование, сокращение дислокационных петель и формирование пор в $\mathrm{ZnS}$ после обучения. При этом в построении изображения было использовано не менее 20 дифрагированных пучков. На рис. 2, а показан снимок дислокационной петли ,plan view“ с высоким разрешением. На рис. 2, $b, c$ показано то же место после облучения через 5 и $15 \mathrm{~min}$ соответственно. Видно сокращение дислокационной петли (рис. 2,b) и образование пор (рис. 2,c), которые формируются в результате скопления вакансий, что свидетельствует о дальнейшей декомпозиции материала под воздействием электронного облучения. При этом сохраняется кристаллическая структура материала, о чем свидетельствует электронограмма, полученная для этого же места образца и приведенная в верхнем правом углу рис. $2, c$.

Типичными дефектами в пленках $\mathrm{ZnS}$, выращенных на подложках (001) GaAs, являются дислокации, дефекты упаковки и микродвойники [12].

Гетеросистема $\mathrm{ZnS} / \mathrm{GaAs}$ характеризуется высоким параметром несоответствия решеток эпитаксиального слоя и подложки. Параметр несоответствия $f$ гетеросистемы $\mathrm{ZnS} / \mathrm{GaAs}$ равен 4.5\%. Эпитаксиальные системы с высоким параметром несоответствия решеток $(f>2 \%)$ характеризуются содержанием большой плотности прорастающих в эпитаксиальную пленку дислокаций. При этом эпитаксиальная пленка $\mathrm{ZnS}$ испытывает напряжение растяжения. Это является причиной формирования экстраплоскостей дислокаций несоответствия в пленке $\mathrm{ZnS}$ на границе $\mathrm{ZnS} / \mathrm{GaAs}$, что можно видеть на снимках с высоким разрешением. Как правило, $60^{\circ}$ дислокации являются основным типом дислокаций несоответствия в $\mathrm{ZnS} / \mathrm{GaAs}$.

Облучение границы раздела $\mathrm{ZnS} / \mathrm{GaAs}$ электронным пучком с энергией $400 \mathrm{keV}$ демонстрирует, что при указанных условиях облучения в слое $\mathrm{ZnS}$ происходят значительные структурные нарушения, в то время как в GaAs изменений еще не наблюдается даже на снимках с высоким разрешением (рис. 3). Такая же закономерность имела место при облучении границы раздела $\mathrm{ZnS} / \mathrm{GaAs}$ электронным пучком с энергией $100 \mathrm{keV}\left(E<E_{T}\right)$ в ПЭМ [1].

При облучении $\mathrm{ZnS} / \mathrm{GaAs}$ электронами с энергией $400 \mathrm{keV}$ наблюдается трансформация прорастающих в эпитаксиальный слой дислокаций, а также формирование пор и мелких частиц новой фазы с размерами $\leq 10 \mathrm{~nm}$ с характерным муаровым контрастом. Микродвойники, наклонные к поверхности раздела пленка-подложка, практически не изменяются при данных условиях облучения. Изменение (разрушение) микродвойников возможно только при больших временах облучения (> $30 \mathrm{~min})$, когда процесс декомпозиции $\mathrm{ZnS}$ практически завершается, что хорошо согласуется 
$a$

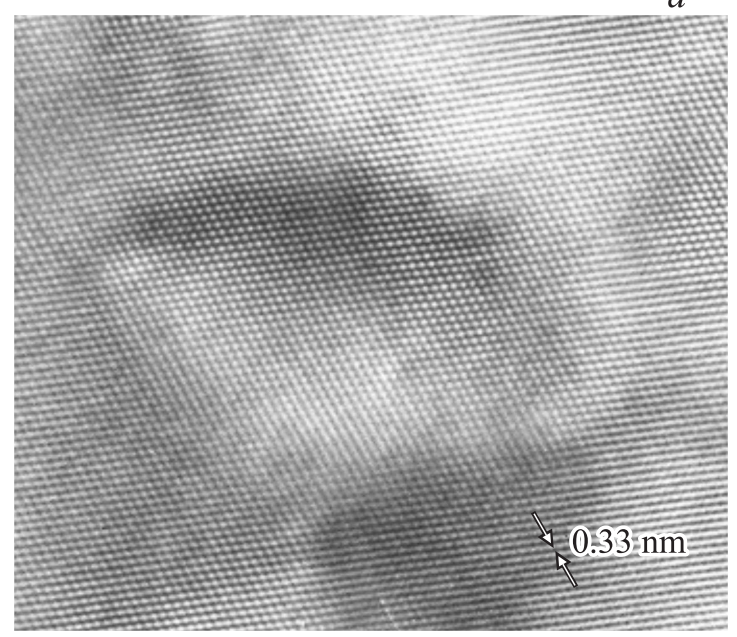

$b$

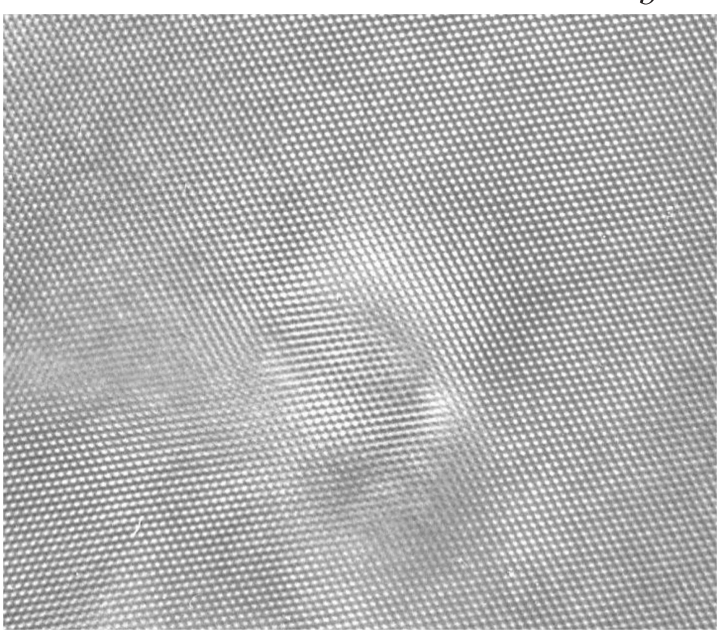

C

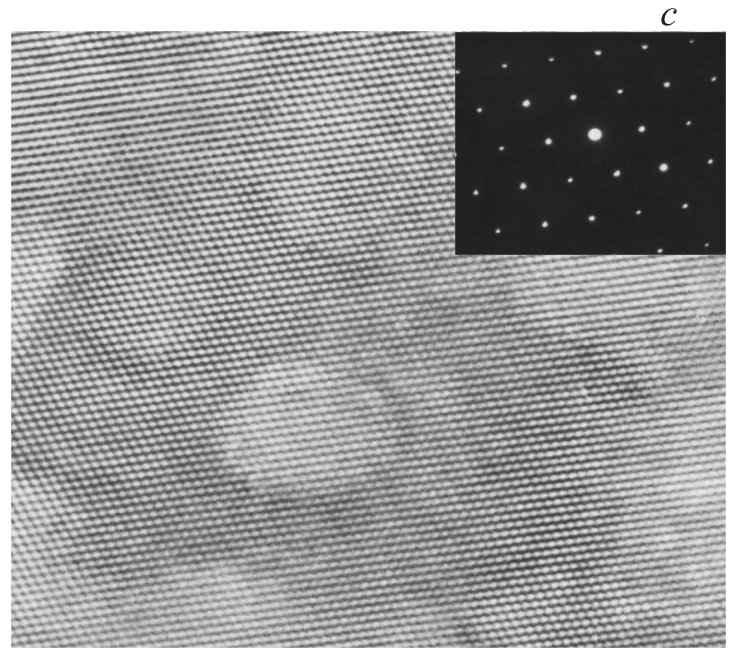

Рис. 2. Электронно-микроскопические изображения с высоким разрешением одного и того же места ZnS после облучения электронами с энергией $400 \mathrm{keV}$ при интенсивности $4 \cdot 10^{19} e / \mathrm{cm}^{2} \cdot \mathrm{s}$. $a-$ сформировавшаяся дислокационная петля, $b, c-$ последующее облучение в течение 5 и $15 \mathrm{~min}$ соответственно. Ось зоны $\langle 110\rangle$.

с закономерностью декомпозиции $\mathrm{ZnS}$, обнаруженной ранее при облучении этого соединения электронами с энергией $100 \mathrm{keV}$ [13].

Формирование современных полупроводниковых приборов ультрамалых размеров требует контроля не только наличия и плотности дефектов типа дислокаций, дислокационных петель, дефектов упаковки и микродвойников, но и контроля дефектов с размерами $\leq 10 \mathrm{~nm}$. Как было показано ранее, формирование новой фазы таких размеров в материалах $A_{2} B_{6}$ возможно под воздействием электронов и ионов $[13,14]$.

Как правило, микроанализ частиц таких размеров технически затруднен. Однако использование техники муарового контраста, формирующегося от частиц на снимках с высоким разрешением, позволяет в определенных случаях установить химический состав этих частиц. При этом период муарового контраста $D$, возникающий при повороте решеток с параметрами $d_{1}$ и $d_{2}$ на угол $\alpha$, можно определить в соответствии с [15].

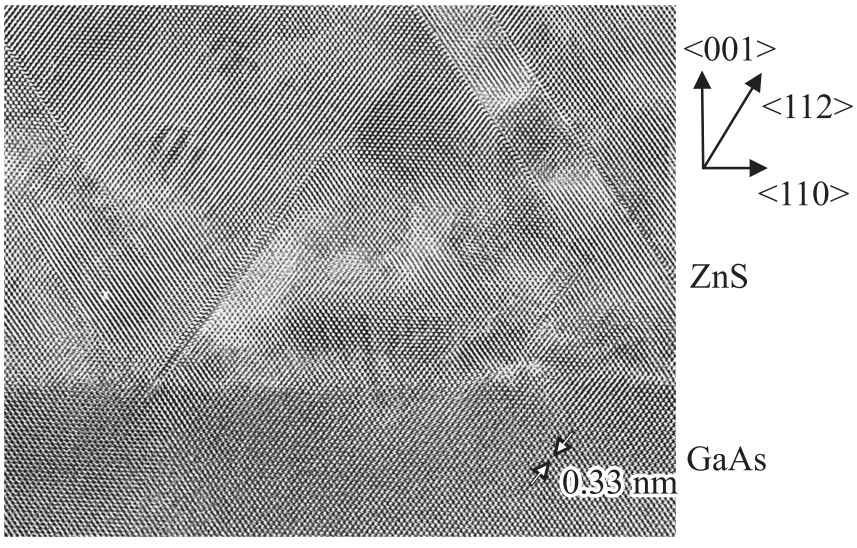

Рис. 3. Электронно-микроскопическое изображение с высоким разрешением поперечного сечения гетероструктуры $\{100\} \mathrm{ZnS} /\{100\} \mathrm{GaAs}$, выращенной методом MOVPE, после 15 min облучения в ПЭМ электронами с энергией $400 \mathrm{keV}$ при интенсивности $4 \cdot 10^{19} \mathrm{e} / \mathrm{cm}^{2} \cdot \mathrm{s}$. 
В результате анализа мелких выделений, формирующихся в кристаллах $\mathrm{ZnS}$, облученных электронами с энергией $400 \mathrm{keV}$, обнаружено, что мелкие выделения с характерным муаровым контрастом могут быть идентифицированы как фаза $\mathrm{ZnO}$ и $\mathrm{ZnO}_{2}$, что согласуется с ранее полученными результатами $[1,14]$. Формирование окислов цинка при электронном облучении может быть обусловлено преимущественным удалением атомов аниона под воздействием электронного пучка [16].

\section{4. Заключение}

Методами просвечивающей электронной микроскопии обнаружено, что облучение кристаллов $\mathrm{ZnS}$ электронами с энергией $400 \mathrm{keV}$ сопровождается образованием дислокационных петель, дальнейшим сокращением и перемещением петель, формированием пор и выделений новой фазы с размерами $\leq 10 \mathrm{~nm}$, которая может быть идентифицирована с помощью анализа муарового контраста как $\mathrm{ZnO}$ и $\mathrm{ZnO}_{2}$. Закономерности формирования структурных дефектов в $\mathrm{ZnS}$ могут быть использованы для решения задач управления типом, плотностью и пространственным распределением дефектов кристаллического строения, что важно для реализации предельных параметров устройств микроэлектроники.

\section{Список литературы}

[1] Ю.Ю. Логинов, П. Браун, К. Дьюроуз. Закономерности образования структурных дефектов в полупроводниках $A_{2} B_{6}$. Логос, М. (2003). 304 c.

[2] В.В. Козловский, А.А. Лебедев, Е.В. Богданова, Н.В. Середова. ФТП 49, 1198 (2015).

[3] L. Fedina, A. Gutakovskii, A. Aseev, J. Van Landuyt, J. Vanhellemont. Phys. Status Solidi A 171, 147 (1999).

[4] О.Г. Грушка, В.Т. Маслюк, С.М. Чупыра, О.М. Мыслюк, С.В. Биличук, И.И. Заболоцкий. ФТП 46, 327 (2012).

[5] S. Lavagne, C. Levade, G. Vanderschaeve. Mater. Sci. Eng. B 128, 1 (2006).

[6] M. Heuken. J. Cryst. Growth 146, 570 (1995).

[7] M. Hirata, M. Kiritani. Physica B + C 116, 616 (1983).

[8] K. Nakai, C. Kinoshita, Y. Muroo, S. Katajima. Phil. Mag. A 48, 215 (1983).

[9] K. Urban. Phys. Status Solidi A 56, 157 (1979).

[10] В.М. Лазаренко, Ю.М. Платов, М.И. Плетнев. ФММ 50, 164 (1989).

[11] H. Abe, T. Ishizaki, F. Li, S. Kano, Y. Li, Y. Satoh, T. Nagase, H. Yasuda. Mater. Trans. 55, 423 (2014).

[12] П.Д. Браун, Ю.Ю. Логинов, У.М. Стоббс, К.Дж. Хамфрейс. ФTТ 38, 284 (1996).

[13] Yu.Yu. Loginov, P.D. Brown. Phys. Status Solidi A 132, 323 (1992).

[14] Y.Y. Loginov, P.D. Brown, C.J. Humphreys. Microsc. Semicond. Mater. 146, 431 (1995).

[15] П. Хирш, А. Хови, Р. Николсон, Д. Пэшли, М. Уэлан. Электронная микроскопия тонких кристаллов. Мир, М. (1967). $574 \mathrm{c}$.

[16] N. Thangaraj, B. Wessels. J. Appl. Phys. 67, 1535 (1990). 